\title{
Equalizing voltage levels in MV distribution network of Elektra Zagreb
}

\author{
I. Sagovac, G. Sagovac \\ HEP-Distribucija d.o.o., DP Elektra Zagreb \\ Gunduliceva 32, 10000 Zagreb (Croatia) \\ phone:+385 1 4601111, fax.: :+385 1 4856329, e-mail: irena.sagovac@hep.hr, goran.sagovac@hep.hr
}

\begin{abstract}
In normal working conditions switching power supply of medium voltage (MV) network from one 110/10 kV or $30 / 10 \mathrm{kV}$ substation to another is conducted almost on daily basis due to different reason, for example maintenance process. This kind of manipulations can cause severe change of voltage levels in low voltage (LV) network powered by 10/0,4 kV substations. This voltage changes can be caused due to voltage drop along the line to which substation is connected to after the switching operation, or due to different voltage levels on MV bus-bars of $110 / 10 \mathrm{kV}$ or $30 / 10 \mathrm{kV}$ substations.
\end{abstract}

This problem was noticed after customers connected to LV network started complaining on problems with supply voltage. Considering networks topology and interconnected $110 \mathrm{kV}$ and $30 \mathrm{kV}$ substations through $10 \mathrm{kV}$ network in distribution area of Elektra Zagreb, it was noticed that most customers' complaints could have been avoided by equalizing voltage levels in MV distribution network.

With the help of data from Elektra Zagreb's permanent power quality monitoring system and additional voltage measurements, equalization of voltage levels in MV distribution network was conducted.

\section{Key words}

MV voltage levels, switching, customers' complaints, voltage measurements, power quality monitoring system

\section{Introduction}

Almost all $110 / 10 \mathrm{kV}$ and $30 / 10 \mathrm{kV}$ substations in distribution area of Elektra Zagreb can be interconnected through $10 \mathrm{kV}$ network.

Switching a part of $10 \mathrm{kV}$ network from one supply substation $(110 / 10 \mathrm{kV}$ or $30 / 10 \mathrm{kV})$ to another can cause change of voltage levels in that network part. For example one $10 / 0,4 \mathrm{kV}$ substation that was at the beginning of a line can after the switching operation end up at the end of another line. Due to voltage drop along the line, voltage level in that substation can be significantly lowered.

Significant voltage level change after the switching manipulation can also be caused by different voltage levels on MV bus-bars of $110 / 10 \mathrm{kV}$ or $30 / 10 \mathrm{kV}$ substations.

This problem was noticed after several customers connected to LV network started complaining on problems with supply voltage. Number of complaints rose in the past decade due to large number of consumer electronics used in households that are very sensitive to voltage change. Number of 10/0,4 kV substations Elektra Zagreb is in charge is approximately 2500.

The reason for different voltage levels on MV bus-bars is historical: before $110 / 10 \mathrm{kV}$ or $30 / 10 \mathrm{kV}$ substations used to supply their own MV network. Voltage levels in MV network were adjusted according to the character of supply: mostly residential, industrial, commercial etc. For example, industrial networks demanded higher voltage levels in order to compensate voltage drop along the lines caused by large loads.

Also, few years back, quality of supply wasn't given much importance. During maintenance procedures customers were being left without electrical supply for a few hours. Today customers' supply interruptions are being avoided at all cost [1]. During downtime in MV network parts, supply of $10 / 0,4 \mathrm{kV}$ substations is switched to other MV networks. In this process voltage 
levels in LV networks can significantly change due to change of voltage levels in supplying MV network.

These changes cause customers' complaints that could have been avoided by equalizing voltage levels in MV distribution network.

Measurements of voltage levels in Elektra Zagreb's 10 $\mathrm{kV}$ distribution network were conducted. Data from permanent power quality monitoring system that exists in Elektra Zagreb was also used for this purpose.

Based on gathered results and thorough analysis, the process of equalizing voltage levels in MV distribution network was done. After this was done, number of customer's complaints was significantly lowered.

\section{Description of the problem}

HEP-ODS Distribution Area Elektra Zagreb is in charge of few tens of 110 and $30 \mathrm{kV}$ substations that are interconnected over $10 \mathrm{kV} \mathrm{MV}$ network. In normal operation due to maintenance, network faults, isolating faulted parts of network etc. switching procedures are conducted on daily basis.

These 110 and $30 \mathrm{kV}$ substations supply different types of customers. Some distribute power to mostly residential areas, others to industrial zones or areas used mostly for commercial purposes. Also, some substations power MV networks that are mostly cable networks others are powering large number of overhead lines [2].

Voltage levels on MV bus-bars powering industrial customers or overhead lines are generally higher then those which are powering cable network. When a switching operation in MV network occurs that as a consequence has powering overhead line from bus-bars that generally power cable network, voltage levels on overhead line can be lowered.

Lowered MV levels are transferred over 10/0,4 kV transformers to LV networks and can cause voltages in LV networks to cross allowed limits.

On the contrary, if voltage levels in MV networks rise, voltages in LV networks will also rise.

On figure 1 is shown an example of voltage drop on 0,4 $\mathrm{kV}$ bus-bars in 10/0,4 kV substation during switching of MV network's supply. Graph shows 10-min RMS voltage values.

In order to establish MV network's voltage level on which most customers will not feel significant voltage change caused by switching operations, overall voltage measurements in MV network were conducted.

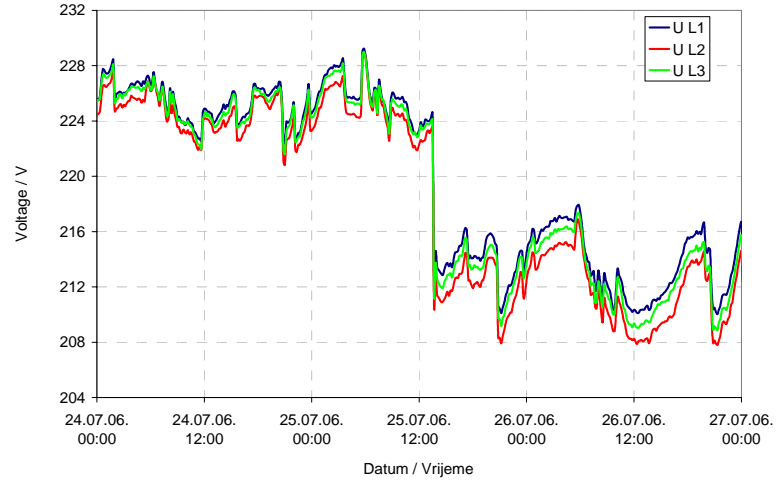

Fig. 1. Voltage on $0,4 \mathrm{kV}$ bus-bars in $10 / 0,4 \mathrm{kV}$ substation caused by switching in MV network

\section{Description of the measurement}

MV network in Elektra Zagreb is powered through five substations 110/30 kV, fourteen substations 110/10(20) $\mathrm{kV}$ and twenty three substations $30 / 10 \mathrm{kV}$.

Since voltage levels had to be measured simultaneously and number of measuring instruments was limited, MV network had to be divided in subgroups. Since $30 \mathrm{kV}$ network of the city Zagreb is supplied through 3 large $110 / 30 \mathrm{kV}$ substations, 3 measuring subgroups were formed, i.e. 3 measuring campaigns.

On figure 2 is shown a subgroup of $110 / 30 \mathrm{kV}$ substation 4TS 28, that powers five substations $30 / 10 \mathrm{kV}$ (3TS 11, 3TS 2, 3TS 3, 3TS 4 and 3TS 6). $10 \mathrm{kV}$ networks of these substations are interconnected.

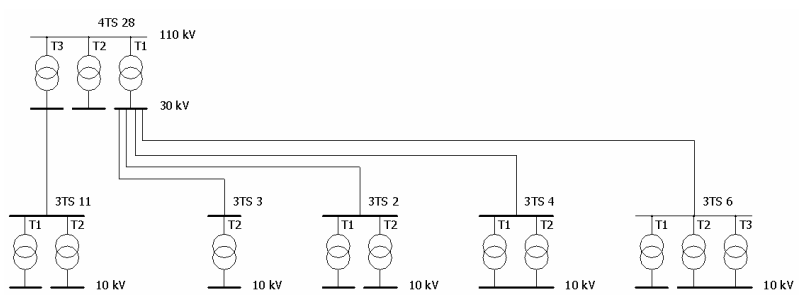

Fig. 2. Part of MV network in which voltage measurement was conducted

During measurements it was necessary to be aware of operating state of transformers' and bus-bars' switch positions in order to establish all the measuring points. In case on fig. 2 there were 8 measuring points on $10 \mathrm{kV}$ bus-bars and 2 measuring points on $30 \mathrm{kV}$ bus-bars.

Substation 3TS 11 has installed instruments that are part of permanent power quality monitoring system. Measuring instruments are connected on MV side of transformers and are collecting power quality data on those $10 \mathrm{kV}$ network's supply points. Information from these instruments was used for purpose of this measurement campaign. 


\section{Measurement results}

Measurements on network's part shown on fig. 2 were conducted during 6 days: from $10^{\text {th }}$ to $16^{\text {th }}$ August 2006 simultaneously in all measuring points.

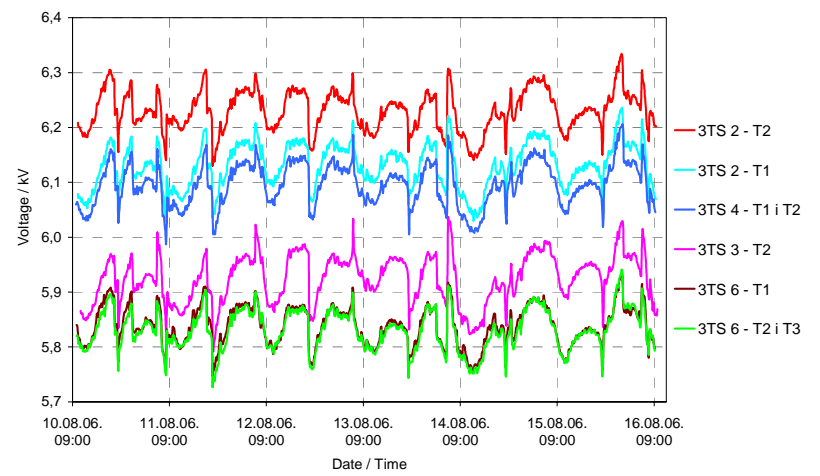

Fig. 3. Measured 10 minute average phase voltages on $10 \mathrm{kV}$ bus-bars in 30/10 kV substations

Graph on fig. 3 shows 10 minute average RMS values of voltages on $10 \mathrm{kV}$ bus-bars in substations supplied by transformer $\mathrm{T} 1$ from substation 4TS 28 (fig. 2). It can be seen that phase voltage levels vary from $5,75 \mathrm{kV}$ to 6,3 $\mathrm{kV}$.

By analyzing measured data minimum, maximum and average value during measurement period were established. Graphical representation of this data is shown on fig. 4. In this graph is also data from 3TS 11 shown.

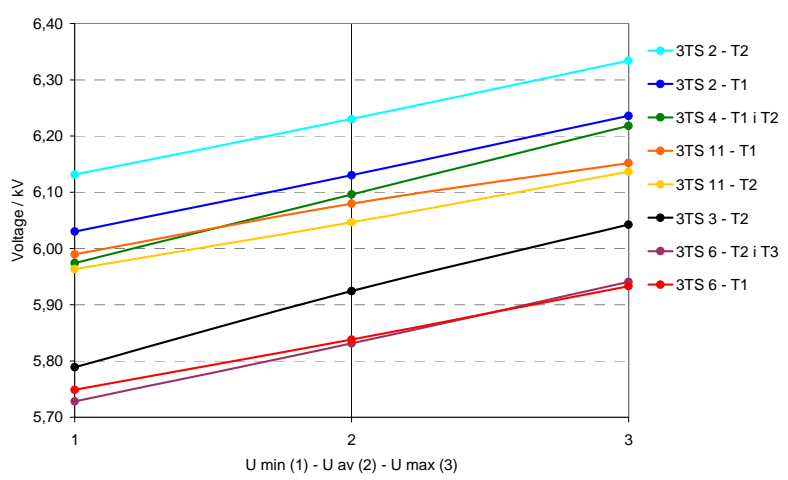

Fig. 4. Minimum, average and maximum voltages recorded during measurement campaign

Form fig. 4 it can be seen that maximum voltage difference exists between T2 in substation 3TS 2 and T1 in 3TS 6 . The difference between average phase voltages is $400 \mathrm{~V}$ or almost $7 \%$. These two substations are situated nearby and during switching power supply of 10 $\mathrm{kV}$ network from one substation to another, voltage change of $7 \%$ can be expected.

In a hypothetical case where a $10 / 0,4 \mathrm{kV}$ substation is supplied from $10 \mathrm{kV}$ network connected to T2 of 3TS 2 (higher voltage level) gets switched to supply from T1 of 3TS 6 (lower voltage level), a voltage drop of $7 \%$ would occur. In case that on LV bus-bars of $10 / 0,4 \mathrm{kV}$ before switching phase voltage is $220 \mathrm{~V}$, after the switching it would drop to $204 \mathrm{~V}$ (- $7 \%$ ), which is well below allowed voltage level of $230 \mathrm{~V}-10 \%$ given by EN 50160 [3].

\section{Equalizing voltage levels}

After all measurements were done, data was analyzed. Value of phase voltage at $6 \mathrm{kV}(10,4 \mathrm{kV}$ line voltage) was established as desirable voltage level in MV network of Elektra Zagreb. The main factor for selecting this value was the least number of necessary adjustments on transformer's tap changers' ratios.

Considering transformers' nominal data (nominal voltages, tap changer's ratios etc.) for each measuring point were necessary changes in tap changer position calculated and according to it new voltage level was established.

In was not possible to achieve ideal $6 \mathrm{kV}$ level on all transformers, but voltages were adjusted as close as possible to that value.

On fig. 5 are shown new values of voltage levels in substations from fig. 2 that were calculated using data obtained from that measurement campaign (shown on fig. 4). Comparing data from fig. 4 with data on fig. 5, it can be noticed that the difference in voltage levels between two extreme values has dropped from $400 \mathrm{~V}(7 \%)$ to 160 $\mathrm{V}(2,8 \%)$.

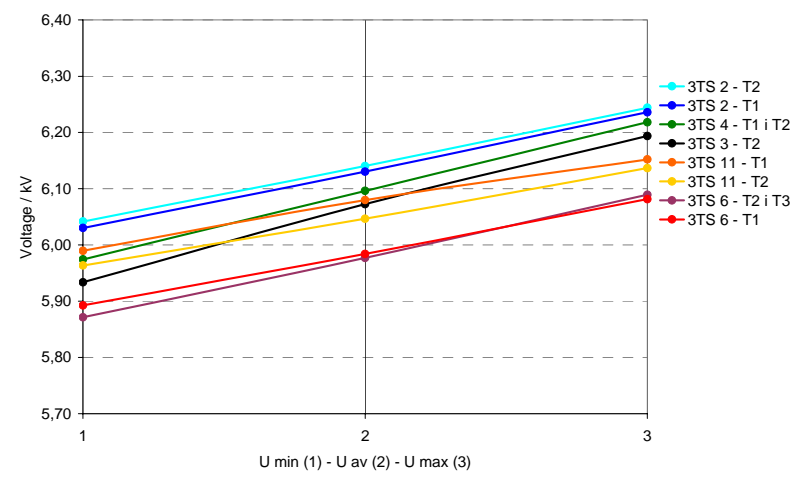

Fig. 5. Calculated minimum, average and maximum voltages after adjustment of tap changers' positions

In most cases, transformer tap changer had to be adjusted by one tap position. Depending on the type of transformer, this change was either $1,5 \%$ or $2,5 \%$. This amount of change in voltage value in MV network shouldn't have big influence in LV network's voltage.

In cases where tap position had to be changed by two positions, additional measurements were conducted in $\mathrm{LV}$ network in randomly selected $10 / 0,4 \mathrm{kV}$ substations, in order to assure that by this change in tap position, allowed voltage limits in LV network wouldn't be crossed.

It was expected that in some extreme cases it would be necessary to adjust voltage levels on LV side of 10/0,4 $\mathrm{kV}$ transformers by changing tap position on them. It was 
established that number of these cases won't be large. In such cases adjustments will be made upon LV customers' complaint or during systematic measurement of transformers' voltage and burden.

By doing these MV voltage level adjustments and equalizing them, possible large number of complaints from LV customers was avoided.

\section{Conclusion}

Normal operating procedures in MV networks include switching from one supply point to another. These switching operations can be caused by maintenance procedures, faults in network, isolating faulted parts of network etc.

Difference in voltage levels on MV bus-bars supplying MV network in which switching occurred, is transferred to LV levels. Since most customers are connected to LV network, it is logical that some of them will be affected by this voltage change, especially if it is a severe one.

If voltage changes significantly, due to big difference in voltage levels on MV bus bars and eventual change of load along the MV line, customers' equipment may malfunction or even get damaged. It can lead to law suits against distribution companies and compensation requests from customers.

In order to avoid LV customers' complaints caused by severe voltage level changes due to changing supply points in MV network, equalization of MV voltage levels on bus-bars was carried through.
It was necessary to simultaneously measure voltages on all MV bus-bars in distribution network in order to establish state of voltage levels, define desired value based on measurement results and calculate tap position changes that needed to be done to obtain desirable voltage level.

After doing so, number of LV customers' complaints was lowered and possible law suits and compensation requests were avoided.

After this was done, level of power quality in LV network was raised and MV distribution network gained more flexibility.

\section{Acknowledgement}

Financial support of company ELOB is gratefully acknowledged.

\section{References}

[1] "Grid code for electrical system", Croatia, Narodne novine no. 36, 2006.

[2] G. Sagovac, I. Klaric: "Study of power quality in electrical distribution networks", 5th syimposium, HO CIGRE, April 25-28, 2004, Zadar, Croatia

[3] EN 50160:1999, "Voltage characteristics of electricity supplied by public distribution systems", CENELEC, 1999. 